\title{
POPLITEAL ARTERY DAMAGE IN CLOSED INJURIES OF THE KNEE
}

\author{
J. A. CHAPMAN
}

From Manchester Royal Infirmary, Manchester

\begin{abstract}
Injury to the popliteal artery is reported in two patients with closed ligament injuries of the knee, and no fracture or dislocation. The importance of careful assessment of the circulation in this type of patient is emphasised.
\end{abstract}

Popliteal artery injuries accounted for $20 \%$ of all vascular injuries in World War II and $25 \%$ in the Korean War (DeBakey and Simeone 1946; Hughes 1958). In the war in Vietnam the popliteal artery was involved in $13 \%$ (Rich, Baugh and Hughes 1969), while in civil practice incidences between $3 \%$ and $9 \%$ have been reported (Morris et al. 1960; Ferguson, Byrd and McAfee 1961; Patman, Poulos and Shires 1964; Drapanas et al. 1970; Bole et al. 1976; Burnett et al. 1976). Injury of the popliteal artery is therefore not very common, but it does have a relatively poor prognosis. When ligation was the standard treatment for major arterial injury, the overall amputation rate was $40 \%$, but the amputation rate after popliteal artery damage was $72 \%$ (DeBakey and Simeone 1946). The repair of large vessels during the Korean War reduced the overall amputation rate to $13 \%$, but that for injury to the popliteal artery, although much improved, was still 32\% (Hughes 1958). The results from Vietnam were much the same (Rich et al. 1969).

In civilian practice, recent reports do show a marked improvement, notably that of Lim et al. (1980), who had no amputations in 31 consecutive patients with popliteal injuries. Many other authors still report amputation rates of over 35\% (Drapanas et al. 1970; Conkle et al. 1975; Alberty, Goodfried and Boyden 1981; Grimley et al. 1981). Clearly, damage to the popliteal artery may still have very serious consequences.

J. A. Chapman. MA. FRCS. Senior Orthopaedic Registrar 38 Belfield Road. Didsbury, Manchester. England.

(.) 1985 British Editorial Society of Bone and Joint Surgery $0301-620 \times / 85 / 3061 \$ 2.00$
What factors affect the result of injury to the popliteal artery? One important factor, agreed by most authors, is the time between injury and treatment. This must depend on early diagnosis, and this in turn depends on active search for vascular changes. The patient with vascular disease will have symptoms of vascular insufficiency; but the patient with an acute knee injury will complain of local pain and not of the effects of the popliteal artery injury.

It is well known that dislocation of the knee often causes vascular damage. Green and Allen (1977) reviewed 245 cases, of which $32 \%$ had a vascular injury. Although arterial injury is relatively rare in fractures of the long bones, only 10 of 355 in the series of Sher (1975), it is recognised that vascular factors must be carefully assessed in patients with fractures of the upper tibia. An open wound focuses attention on soft tissues and blood vessels. Early diagnosis of injury to the popliteal artery is usual when knee injury presents with an open wound or a fracture or a dislocation; it is less well appreciated that arterial damage can occur in other circumstances.

\section{CASE REPORTS}

Two cases of damage to the popliteal artery are presented. The primary problem in each appeared to be a ligament injury without dislocation, fracture or open wound.

Case 1. A 24-year-old motor cyclist had an accident caused by a tyre blowing out. His right leg probably hit some railings and he had a painful swollen right knee. The pulses in this leg were difficult to detect but were thought to be present. The capillary return seemed normal and the circulation was considered to be satisfactory. Radiographs showed no fracture. Examination under anaesthesia revealed some cruciate laxity and 


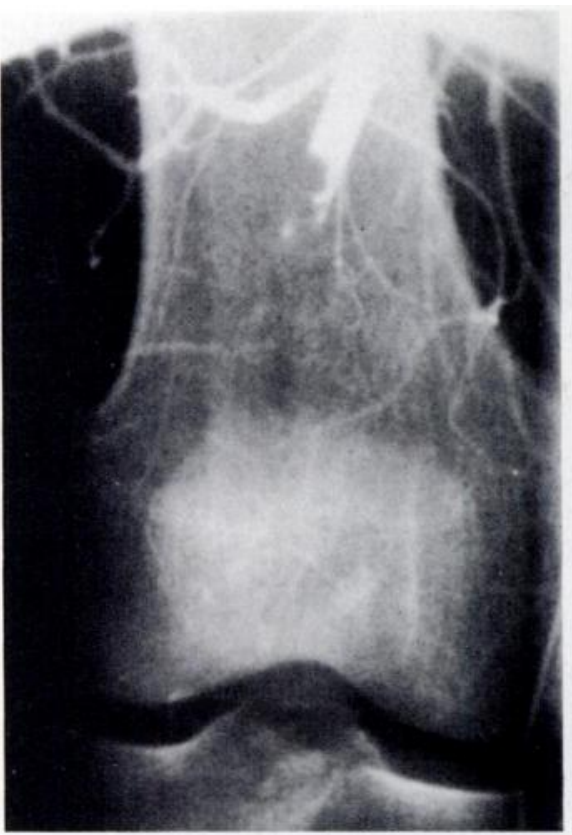

Fig. 1

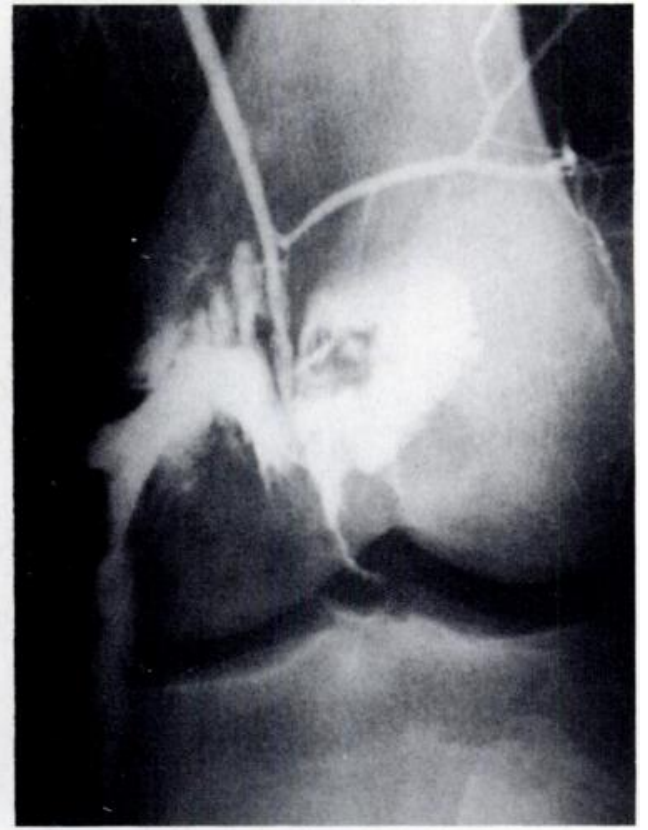

Fig. 2

Figure 1-Case 1. Arteriogram showing occlusion of the popliteal artery. Figure 2-Case 2. Arteriogram showing occlusion of the popliteal artery; extravasation of dye was thought to be due to attempted thrombectomy with a Fogarty catheter before the arteriogram.

opening of the medial joint compartment with valgus stress. Treatment was conservative.

The following morning the circulation still caused some concern. An arteriogram showed a complete block of the popliteal artery (Fig. 1). At operation this artery was found to be completely transected $12.5 \mathrm{~cm}$ proximal to the joint line of the knee. The use of a Fogarty catheter produced good flow and good back bleeding, and an end-to-end repair of the artery was performed. After operation the circulation was satisfactory.

After this the patient developed a deep ulcer on the right heel and a fixed equinus deformity of the right ankle. Desloughing was needed before the ulcer eventually healed. Operation for the equinus deformity was performed 21 months later; the deformity was mainly due to tenodesis of the medial tendons, and when these had been released the foot could be placed in a neutral position. Two-and-a-half years after injury the patient has very limited movement at the ankle and impaired sensation over the right foot. Despite this he walks well and works as a stacker-truck driver without difficulty.

Case 2. A 19-year-old motor cyclist was hit by a car and sustained an injury of the left knee. The mechanism of the injury was uncertain. On arrival at hospital the knee was very swollen and the medial compartment opened on stressing. The circulation was reported to be satisfactory.

At operation, under tourniquet control, the medial ligament was found to be disrupted and was repaired. After removal of the tourniquet, the foot remained ischaemic with poor capillary return and no palpable pulses. The knee was re-explored; there was no significant haematoma in the popliteal fossa. A Fogarty catheter was passed down from the femoral artery but would not pass beyond the popliteal region. Some clot was removed but there was no improvement in the circulation. An arteriogram showed complete blockage of the popliteal artery (Fig. 2), with some extravasation of dye possibly due to trauma from the Fogarty catheter. The popliteal artery was then explored. An intimal tear was found and a saphenous vein graft was inserted. The leg was decompressed by fasciotomy of the muscle compartments. Postoperatively the circulation was satisfactory but the leg remained swollen for a considerable time and the fasciotomy wounds were slow to heal. One area required a skin graft, but the patient eventually became mobile and was able to return to work. 


\section{DISCUSSION}

Most of the popliteal artery injuries reported in the literature are associated with open wounds-such as those from gunshot, stabs, open fractures or operations. Most of the closed injuries are associated with fractures or dislocations, though some authors report injuries produced by blunt instruments (Fabian et al. 1982). In some reports the cause of the injury is not mentioned Table I). None of these reports mentions vascular injury associated with closed ligament injury in the absence of fracture or dislocation. The two cases reported here demonstrate that this can occur.

In what ways can an artery be damaged? Drapanas et al. (1970), discussing arterial injuries in general, classified the causes as perforation, transection, laceration, fracture of intima with thrombosis, arteriovenous fistula or false aneurysm. They considered that fracture of the intima with secondary thrombosis was the usual mechanism of injury caused by blunt trauma. In Case 1, however, the artery was transected. In Case 2 it would seem most likely that the intima was damaged at the time of injury and the thrombosis occurred when the tourniquet was in use during the first operation.
Wood and Stutzman (1963) described five cases of intimal separation. Two of these were in the popliteal artery, one associated with a fracture and the other with dislocation. Hare and Gaspar (1971) described nine cases of what they call "the intimal flap" and reviewed 49 other cases from the literature. Seven of their cases were in the popliteal artery, five being associated with a fracture or a dislocation. No mechanism for injury was specified for the other two.

In this type of arterial injury, one problem is that arterial insufficiency can progress slowly due to late occlusion of collaterals by retrograde thrombosis, and pressure from haemorrhage and oedema. Many authors emphasise that foot pulses may be present initially in patients with damage to the popliteal artery. It is thus very important that the vascular status be assessed, not only at the first examination, but also repeatedly over the ensuing hours and days. The cases presented here emphasise the need for vigilance not only in cases with fracture or dislocation, but in all patients presenting with significant injuries of the ligaments of the knee.

The author is most grateful to $\mathrm{Mr} \mathrm{B}$. Maltby and the late $\mathrm{Mr} \mathrm{J}$. L. Griffiths for permission to publish their cases and to Mrs Deborah Barton for secretarial assistance.

Table I. The causes of popliteal artery injury reported in 20 papers

\begin{tabular}{|c|c|c|c|c|c|c|}
\hline \multirow[b]{2}{*}{ Authors } & \multirow[b]{2}{*}{$\begin{array}{l}\text { Number of } \\
\text { cases }\end{array}$} & \multirow{2}{*}{$\begin{array}{l}\text { Open injury } \\
\text { (gunshot, stab, } \\
\text { compound } \\
\text { fracture) }\end{array}$} & \multicolumn{4}{|c|}{ Closed injury } \\
\hline & & & $\begin{array}{l}\text { Blunt } \\
\text { instrument }\end{array}$ & $\begin{array}{l}\text { Fracture or } \\
\text { dislocation }\end{array}$ & Operation & Not specified \\
\hline Fabian et al. 1982 & 164 & 116 & 15 & 25 & 8 & \\
\hline Snyder 1982 & 110 & 81 & & 29 & & \\
\hline Snyder et al. 1979 & 83 & 61 & & 22 & & \\
\hline Green and Allen 1977 & 41 & & & 41 & & \\
\hline Holleman and Killebrew 1981 & 32 & 25 & & 7 & & \\
\hline Lim e't al. 1980 & 31 & 22 & & 9 & & \\
\hline Conkle el al. 1975 & 27 & 13 & & 14 & & \\
\hline Daugherty. Sachatello and Ernst 1978 & 27 & 13 & & 14 & & \\
\hline Grimley et al. 1981 & 23 & & & 23 & & \\
\hline Alberty et al. 1981 & 20 & & & 20 & & \\
\hline Brewer et al. 1969 & 16 & 9 & & 7 & & \\
\hline Drapanas et al. & 14 & & & & & 14 \\
\hline Ferguson el al. 1961 & 14 & & & & & 14 \\
\hline Morris el al. 1960 & 14 & & & & & 14 \\
\hline Bole et al. 1976 & 12 & & & & & 12 \\
\hline Eger et al. 1972 & 10 & 6 & & 4 & & \\
\hline Burnett et al. 1976 & 8 & & & & & 8 \\
\hline Patman el al. 1964 & 7 & & & & & 7 \\
\hline Dart and Braitman 1977 & 5 & & & 5 & & \\
\hline Houck 1977 & 4 & & 1 & 3 & & \\
\hline
\end{tabular}




\section{REFERENCES}

Alberty RE, Goodfried G, Boyden AM. Popliteal artery injury with fractural dislocation of the knee. Am J Surg 1981;142:36-40.

Bole PV, Purdy RT, Munda RT, Moallem S, Devanesan J, Clauss RH. Civilian arterial injuries. Ann Surg 1976;183:13-23.

Brewer PL, Schramel RJ, Menendez CV, Creech O Jr. Injuries of the popliteal artery: a report of 16 cases. Am J Surg 1969;118:36-42.

Burnett HF, Parnell CL, Williams GD, Campbell GS. Peripheral arterial injuries: a reassessment. Ann Surg 1976;183:701-9.

Conkle DM, Richie RE, Sawyers JL, Scott HW Jr. Surgical treatment of popliteal artery injuries. Arch Surg 1975;110:1351-4.

Dart CH Jr, Braitman HE. Popliteal artery injury following fracture or dislocation at the knee: diagnosis and management. Arch Surg 1977;112:969-73.

Daugherty ME, Sachatello CR, Ernst CB. Improved treatment of popliteal artery injuries using anticoagulation and extra-anatomic reconstruction. Arch Surg 1978;113:1317-21.

DeBakey ME, Simeone FA. Battle injuries of the arteries in World War II: an analysis of 2,471 cases. Ann Surg 1946;123:534-79.

Drapanas T, Hewitt RL, Weichert RF III, Smith AD. Civilian vascular injuries: a critical appraisal of three decades of management. Ann Surg 1970;172:351-60.

Eger M, Golcman L, Schmidt B, Hirsch M. Problems in the management of popliteal artery injuries. Surg Gynecol Obstet 1972;134:921-6.

Fabian TC, Turkleson ML, Connelly TL, Stone HH. Injury to the popliteal artery. Am J Surg 1982;143:225-8.

Ferguson IA, Byrd WM, McAfee DK. Experiences in the management of arterial injuries. Ann Surg 1961;153:980-6.
Green NE, Allen BL. Vascular injuries associated with dislocation of the knee. J Bone Joint Surg [Am] 1977;59-A:236-9.

Grimley RP, Ashton F, Slaney G, Batten RL. Popliteal arterial injuries associated with civilian knee trauma. Injury 1981:13:1-6.

Holleman JH Jr, Killebrew LH. Injury to the popliteal artery. Surg Gynecol Obstet 1981;153:392-4.

Hare RR, Gaspar MR. The intimal flap. Arch Surg 1971;102:552-5.

Houck WS. Blunt trauma to popliteal artery: a review and a presentation of four cases. Am Surg 1977:43:434-7.

Hughes CW. Arterial repair during the Korean war. Ann Surg 1958; 147:555-61.

Lim LT, Michuda MS, Flanigan DP, Pankovich A. Popliteal artery trauma: 31 consecutive cases without amputation. Arch Surg 1980:115:1307-13.

Morris GC Jr, Beall AC Jr, Roof WR, De Bakey ME. Surgical experience with 220 acute arterial injuries in civilian practice. Am J Surg 1960;99:775-81.

Patman RD, Poulos E, Shires GT. The management of civilian arterial injuries. Surg Gynecol Obstet 1964;118:725-38

Rich NM, Baugh JH, Hughes CW. Popliteal artery injuries in Vietnam. Am J Surg 1969;118:531-4.

Sher MH. Principles in the management of arterial injuries associated with fracture/dislocations. Ann Surg 1975:182:630-4.

Snyder WH III, Watkins WL, Whiddon LL, Bone GE. Civilian popliteal artery trauma: an eleven year experience with 83 injuries. Surgery 1979;85:101-8.

Snyder WH III. Vascular injuries near the knee: an updated series and overview of the problem. Surgery 1982;91:502-6.

Wood NE, Stutzman FL. Intimal separation in arterial injuries Angiology 1963:14:265-7. 